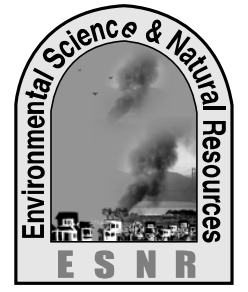

J. Environ. Sci. \& Natural Resources, 7(1): 233-239, 2014

ISSN 1999-7361

\title{
Threats to the Teknaf Wildlife Sanctuary of Bangladesh
}

\author{
S. Alam ${ }^{1}$, K. Misbahuzzaman ${ }^{2}$, M. A. Rahman² and M. H. Kabir ${ }^{2}$ \\ ${ }^{1}$ UNHCR, Bangladesh \\ ${ }^{2}$ Institute of Forestry and Environmental Sciences, University of Chittagong, Bangladesh \\ ${ }^{3} \mathrm{ACF}$, Bangladesh Forest Department, Bangladesh
}

\begin{abstract}
Loss of wildlife, encroachment on forest lands and illegal cutting of trees are the major culprits of management of protected areas (PAs) of Bangladesh. To increase support from local communities and ensure long-term sustainability for Forest PAs in Bangladesh, including Teknaf Wildlife Sanctuary (TWS), community-based conservation approach was introduced by Bangladesh Forest Department. In this study, the effectiveness of forest co-management approach for reducing threats was assessed through key informant interviews, and focus group discussions (FGDs) at TWS. Secondary data were also collected from official document reviews, project reports, journals, books. The study found six direct threats at TWS. Among these, wood collection was the most severe threat. The findings also revealed that, through threat reduction indices, illegal logging, encroachment and hunting, grazing was reduced at a great extent in TWS. We suggest that continuation of co-management of TWS can conserve its natural resources in a sustainable way.
\end{abstract}

Key Words: Protected areas, Teknaf Wildlife sanctuary, Threat reduction assessment

\section{Introduction}

The world's total forest area is just over 4 billion hectares, corresponding to 31 percent of the total land area or an average of 0.6 ha per capita (FAO, 2010) and is critical in meeting human needs for water, food, shelter, medicine, fuel wood, fodder and timber. It also provides a wide range of environmental services which mainly include biodiversity conservation, watershed protection, protection of soil, mitigation of global climate change (Hirakuri, 2003). In Bangladesh, tropical evergreen and semi evergreen forests are extended over Chittagong, Cox's Bazar, Chittagong Hill Tracts and Sylhet totaling an area of 6,70,000 hectare which is $4.54 \%$ of total landmass of the country and $44 \%$ of national forest land. The largest single tract of natural mangrove forest is the Sundarban. It consists of a total of $6,01,700$ hectare which is $4.07 \%$ of total land mass of the country and $40 \%$ of total forest land. Besides, the Central and northern districts covering an area of 1,20,000 ha about $0.81 \%$ of total land mass of the country and $7.8 \%$ of the country's forest land are bestowed with Tropical Moist Deciduous Forests. Tree coverage in the village forests are 2,70,000 hectare which acts as the source of a remarkable portion of national demand of forest produces. The latest inventory exhibits that a total of 54.7 million cubic metres forest products are available in this village forests (BFD, 2014). In last several decades, deforestation and biodiversity loss became a common event throughout the globe. This phenomenon is much more frequent in developing countries like Bangladesh. During the last two or three decades the forest cover of the country decreased from nearly $20 \%$ to $9 \%$ (Brown and Durst, 2003). As a signatory of various regional and international conventions, treaties and protocols, government of Bangladesh has taken various initiatives to reduce the rapid deforestation and to ensure the conservation of remaining floral and faunal diversity. Declaration of natural forests as
'Protected area' (PA) is one amongst them which introduced mainly to conserve biodiversity in its natural context. Ideally, PAs help to conserve the forest and biodiversity. Declaration of PAs however, imposes some restrictions on the access and utilization of forest products to local livelihoods that they have enjoyed customarily.

PAs have long been considered as the cornerstone of all national and regional conservation strategies. Therefore, conflicts occur between PA managers and local indigenous and traditional people. Such misunderstanding is one of the most influential factors of poor and inefficient management of protected areas. Non-timber forest products attracts the attention of practitioners, researchers, educators and policy makers amongst various forest products; due to their great potentiality for poverty alleviation (Ruiz Perez, 2005; Arnold and Ruiz Perez, 1999). They also create opportunities to development of forest based small scale enterprises (FBSSE) and it is widely recognized that, increasing their commercial value will contribute to increased appreciation of forests, therefore contributing to both poverty alleviation and forest conservation (Clay, 1992).

In Bangladesh, there are 34 PAs with an area of 0.27 million hactres (BFD, 2014). By definition, a PAs is an area where everything is prohibited unless permitted. Such definition implies that the forest is practically free from all public activities (i.e., all types of commercial harvesting of timber and non- timber forest products). However due to poor socio-economic background such definition turns to be a hypothetical conception and traditionally people living in or near Bangladesh PAs exploit various forest resources from the park for their subsistence. Due to recent consciousness on PAs, peoples are now limitedly allowed for such practice. PAs are dominant areas for people in Bangladesh and play a vital role in their subsistence as well as in income. 
Collaborative management of forest resources defines as "a situation in which two or more social actors negotiate, define and guarantee among themselves a fair sharing of management functions, entitlements and responsibilities for a given territory, area or a set of natural resources" (Roy, 2004). The key elements are involvement of resource users/stakeholders in forest protection; sharing of management functions with explicit delineation of roles and responsibilities and clear cut definition of rights and entitlements. In TWS, Nisorgo, a concern of USAID, Bangladesh, has established two-tier forest co-management institutions. These are co-management committee and council with the participation of people from all walk of lives. Each committee consists of 29 members and each council consists of 65 members (Rahman, 2011). Nisorgo has established environment library (6) and club (6) for the stalk holders which is very praiseworthy, and they are providing training on biodiversity conservation, forest nursery, wood preservation, plantation techniques, vegetables cultivation, watershed conservation, climate change and forest, to the stakeholders to protect the TWS. The present activities of IPAC, supported by USAID, Bangladesh, include counseling and organizing committee, village conservation forum, people forum, Nishorgo students club, Nishorgo (Environment) school Library, Nishorgo support programmes, Eco-tour guide and Hinkings.

Despite all above activities, deforestation and forest degradation could not be abated totally. The 'forest' area coverage within the TWS has been decreasing gradually. It was about 3,304 hectare $(28.4 \%)$ in 1989 ; 2,812 hectare $(24.2 \%)$ in $1997 / 2000$; and 1,794 hectare $(15.4 \%)$ in 2009 . From 1989 to 2009 it was reduced by $45.7 \%$ of the forest area. The 'Herb/Shrub/Bush' area was found to be 6,263 hectare $(53.9 \%)$ in 1989 . It had increased to 6,994 hectare $(60.2 \%)$ in $1997 / 2000$ and 7,824 hectare $(67.4 \%)$ in 2009 (CEGIS, 2011). In the backdrop of above circumstances, it is felt necessary to identify threats in conservation of TWS and to what extent threats are reduced due to practice of forest comanagement.

So far, no study has conducted to assess the threats and threat reduction assessment of TWS in Bangladesh. So, the study aimed to identify the threats and to determine the threat reduction by different activities of forest department and NGOs of this protected area. Finally, this draws some recommendation for the conservation and better management of the TWS.

\section{Materials and Methods}

\subsection{Description of Study Area}

The Teknaf Wildlife Sanctuary (TWS) is situated in the middle part of the Teknaf peninsula from Ukhia south to the town of Teknaf. It is located in the country's far south-eastern corner, near to Myanmar border (Figure 1). The climate of the TWS (in general warm and humid) is characterized by 3 seasons winter, summer and monsoon rains. The humidity is high in the TWS throughout the year, with monthly average humidity varying from $27.6 \%$ in April to $98.6 \%$ in (Rahman, 2011). There is heavy dew during winter when rainfall is low. The water condensation is thus distributed throughout the year in different forms and greatly influences plants and monsoon rains. The temperature varies on an average from 15.4 degrees in January to 25.4 degrees in May (Roy, 2005) humidity is high in the TWS throughout the year, with monthly average humidity varying from monsoon rains.

The area is traverse by numerous creeks that are clear with gravel and stony beds that flow down to the Naf River on the eastern side and to the Bay of Bengal on the western side. There are a number of other small streams and shallow depressions, which are wetlands providing marshy sanctuaries to migratory birds and livelihood to local fishermen. They provide good habitat, drainage and drinking water source for the wild animals and local people. So aquatic habitats associated with forest cover and riparian (streamside) vegetation and animal species are important part of overall habitat composition. It was established in 1983 (vide Notification No. XIII/For-65/83/770 dated 17th November, 1983) over a Reserved Forest (RF) area of 28,688 acres 11,610 ha) covering $10 \mathrm{RF}$ blocks (Rahman, 2011). Reconginizing its importance for biodiversity conservation, the government of Bangladesh has declared it as Teknaf wildlife sanctuary in 2009 (GOB, 2009).

\subsection{Data Collection}

For the study both primary and secondary data were collected. We applied focus group discussions (FGDs), key informants' interview and field visit, for data collection. Focus Group Discussion (FGD) in each forest beat was carried out under TWS and 10 FGDs were conducted in total. FGD participants were members of Co-Management Committee, forest dependent people, and Village Common Forests. There were 10 to 12 participants in each FGD. Participants who were interviewed as KI (key informant) include 10 forest beat officers, 2 forest range officers, 10 forest guards, 1o forest Malies, 10 forest village headmen, 5 police sub-inspectors, 1 police inspector as OC (officer in charge), Ukhia Thana, The UNO (Upazilla Nirbahi Officer), The Upazilla Chairman, 10 political leaders ( treasury bench and opposition), 10 civil society members. The study was carried out within a time span of six months ranging from April, 2011 to October 2011. 

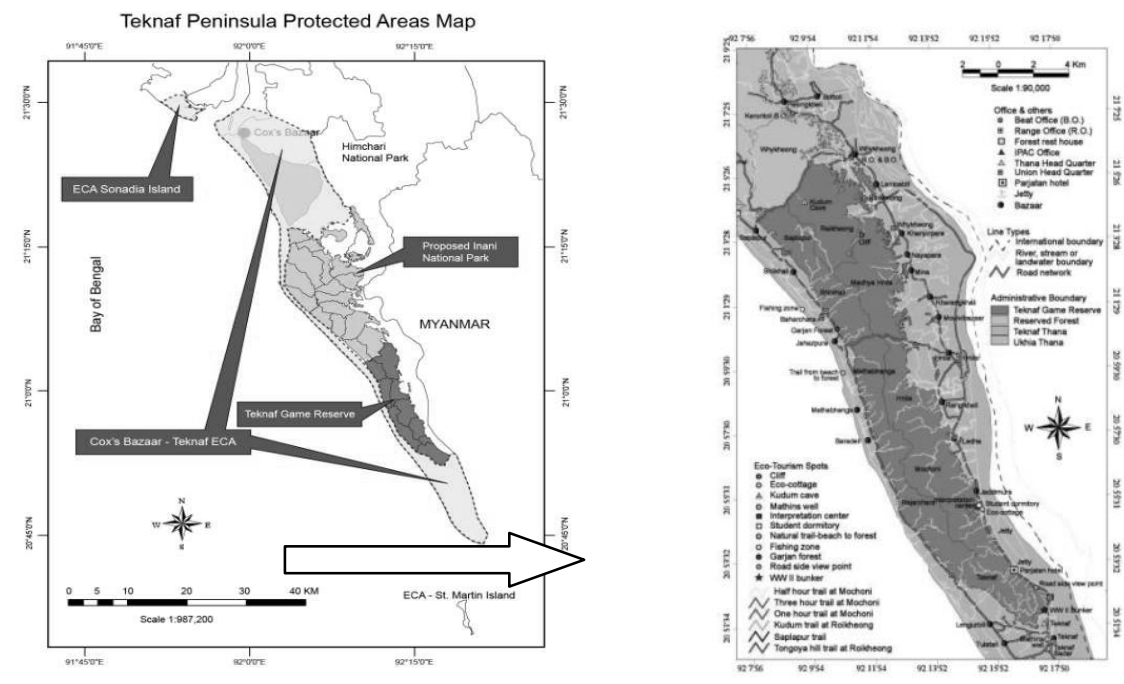

Fig. 1. Map of Teknaf Wildlife Sanctuary (Source: IPAC, 2009)

\subsection{Data analysis}

Lists of all direct threats were developed on the worksheet, in the column headed threats. Each threat was ranked on the basis of its affecting area. The threat which possessed the largest area was ranked as top which scored the maximum point, equal to the total number threats, and goes down successively with respect to affected area by this threat. After that, the total of the ranking points were added and recorded at the bottom of the column. Following the same procedure, each threat was again ranked on the basis of impact or severity of destruction, and urgency i.e. most urgent threats to least urgent threats. At the next stage, the respective score of each threat in three categories, viz on the basis of area, impact and urgency, total score for each threat was calculated across the three columns. And then, the total scores were added in the column headed 'total ranking' and recorded at the bottom of the column. At next, the degree of threat reduction in percentage was calculated on the basis of results from FGDs. To calculate raw score of each threat, the total ranking was multiplied with the threat reduction percentage. By adding these scores, total raw score was calculated which used to determine the threat reduction assessment (TRA) index. Finally, in this way, the TRA index was calculated for each threat. For every beat, both separate and mean TRA index of threats was calculated following a formula (Richard and Nicksalaski, 2001).

\section{Results and Discussion}

\subsection{Threats of TWS}

The study found that at TWS, six direct threats are responsible for the depletion of biodiversity. Among the 10 beats of this wildlife sanctuary, Teknaf, Mochoni, and Shaplapur was under all these threats. Interestingly, we also found that Mathabanga beat was under less threat of biodiversity loss (Table 1).

Table 1: Prevailing threats and its distribution in different beats of Teknaf Wildlife Sanctuary, Bangladesh

\begin{tabular}{|c|c|c|c|c|c|c|c|c|c|c|}
\hline \multirow{2}{*}{ Threat } & \multicolumn{10}{|c|}{ Forest beats of Teknaf Wildlife Sanctuary } \\
\hline & $\mathrm{T}$ & Mo & $\mathrm{Sr}$ & $\mathrm{Rg}$ & $\mathrm{W}$ & MH & $\mathrm{H}$ & $\mathrm{Ra}$ & $\mathrm{Ma}$ & $\mathrm{Sh}$ \\
\hline Fuel wood collection & $\sqrt{ }$ & $\sqrt{ }$ & $\sqrt{ }$ & $\sqrt{ }$ & $\sqrt{ }$ & $\sqrt{ }$ & $\sqrt{ }$ & $\sqrt{ }$ & $\sqrt{ }$ & $\sqrt{ }$ \\
\hline Illegal felling & $\sqrt{ }$ & $\sqrt{ }$ & $\sqrt{ }$ & $\sqrt{ }$ & $\sqrt{ }$ & $\sqrt{ }$ & $\sqrt{ }$ & & $\sqrt{ }$ & $\sqrt{ }$ \\
\hline Hunting & $\sqrt{ }$ & & $\sqrt{ }$ & $\sqrt{ }$ & $\sqrt{ }$ & & & $\sqrt{ }$ & & \\
\hline $\begin{array}{l}\text { Encroachment for } \\
\text { settlement }\end{array}$ & $\sqrt{ }$ & $\sqrt{ }$ & $\sqrt{ }$ & & $\sqrt{ }$ & $\sqrt{ }$ & $\sqrt{ }$ & & & $\sqrt{ }$ \\
\hline Encroachment for cropfield & $\sqrt{ }$ & $\sqrt{ }$ & $\sqrt{ }$ & $\sqrt{ }$ & & $\sqrt{ }$ & $\sqrt{ }$ & $\sqrt{ }$ & & $\sqrt{ }$ \\
\hline Grazing of livestocks & $\sqrt{ }$ & $\sqrt{ }$ & $\sqrt{ }$ & $\sqrt{ }$ & $\sqrt{ }$ & $\sqrt{ }$ & $\sqrt{ }$ & $\sqrt{ }$ & $\sqrt{ }$ & $\sqrt{ }$ \\
\hline
\end{tabular}

Note: $\mathrm{T}=$ Teknaf, $\mathrm{Mo}=$ Mochoni, $\mathrm{Sr}=$ Shaplapur, Rg= Roikhong, W= Whykong, MH= Modha Hnila, H= Hnila, Ra= Rajachara, Ma= Mathabanga, $\mathrm{Sh}=$ Shilkhali

\subsection{Threats reduction in TWS}

\section{a. Illegal cutting of trees}

In TWS, on an average, illegal cutting of trees have been found reduced about $52 \%$. Highest percentage
(80\%) of threat (Illegal cutting of trees) has been reduced in Whykong and Shilkali beat while only 10\% 
threats be reduced in Shaplapur beat which is considered very low (Figure 2). Though this percentage was not quite high, but considering time

span of preventing initiatives progresses was praiseworthy.

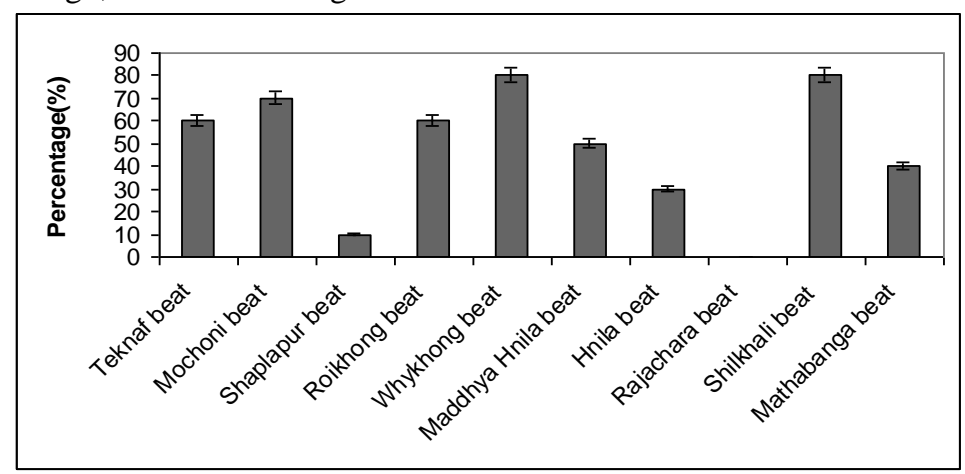

Fig. 2. Reduction of illegal cutting of trees in TWS (need to put correct figure and standard deviation in all the figures)

This threat was found in almost every beat in TWS except Rajachara beat(Table 1).With the support of FD and Nishorgo tree cutting have been reduced in Whykhong, Shilkhali, Mochoni beat area but it still severe in Shaplapur, Hnila and Mathabanga beat because of illegal cutting of trees by Rohingya people from Myanmar.

\section{b. Collection of fuel wood}

Collection of fuel wood was reduced only on an average $21 \%$ at Shaplapur, Roikhong and Whykhong beat. On the other hand, maximum reduction i.e. $50 \%$ was at Teknaf beat while least in Mochoni, Shilkali, Hnila, Maddhya Hnila (only 10\%) (Figure 3).

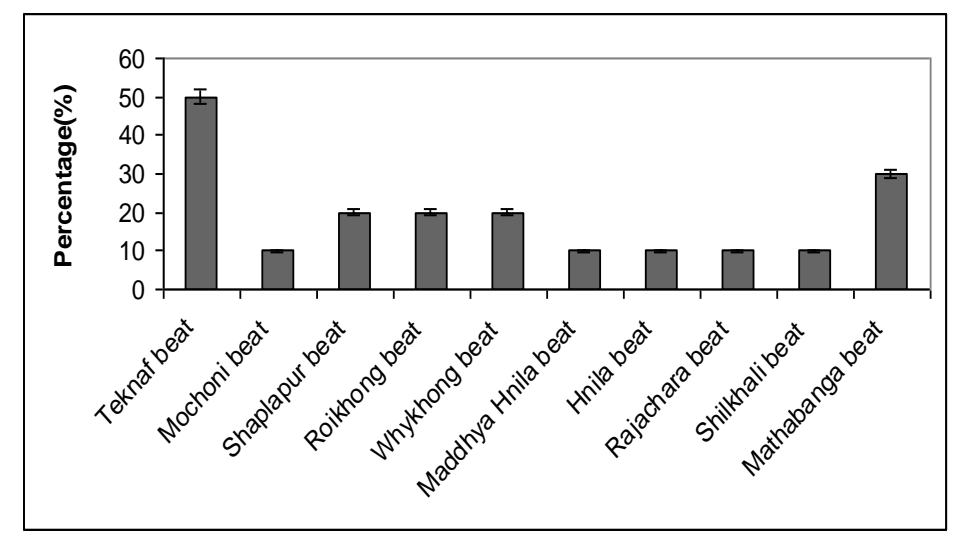

Fig. 3. Reduction of collection of fuel wood in TWS

Though FD and Nishorgo has been discouraging local people about fuel wood collection, they become able to successfully reduced it in Teknaf and Mathabanga beat area but still it is difficult to reduce it in Mochoni, Shilkhali , and Maddhya Hnila beat. Overall only 21\% collection of fuel wood has reduced in entire TWS. People of Teknaf peninsula meet their fuel wood demand from forest and homestead. They have no alternative source of fuel for cooking and other purposes. Disadvantaged and poor people of the region greatly depend on forest for their livelihoods. They gathered in group including men, women, and children in forest for collecting fuel wood. They sell it to the markets to lead their livelihood. For this reason, the reduction of collection of fuel wood at all the forest beats of TWS was not praiseworthy.

\section{c. Encroachment for the expansion of crop-field}

Encroachment for the expansion of crop-field were more reduced in Teknaf and Mochoni, which was about $80 \%$, compared to Shilkali (10\%) and Maddhya Hnila (15\%). On the other hand, average reduction of this threat was about $49 \%$ considering all the beats (Figure 4).

Betel leaf cultivation (1000 ha) is quite a popular activity in and around the TWS and a large number of people (2000 households) depends on it for their livelihood. Most of the betel leaf cultivation areas (800ha) are located on the western side of the TWS particularly in Shaplapur, Shilkhali and Jahazpura. For this reason, forest land is encroached for establishing a betel leaf vein that is vacated after harvesting the betel leaves. In view of its popularity it seems that betel leaf cultivation is found more profitable than paddy cultivation by local cultivators. In addition to this, cultivation of betel nut is planted by around 2500 households through encroach the forest land to earn immediate cash. 


\section{d. Expansion for settlement}

The study found that only $40 \%$ expansion for settlement were reduced compared to the other threats and highest percentage of settlements were reduced at
Mochoni (70\%) while lowest in Maddhya Hnila and Shilkali 10\% (Figure 5). On an average, expansion for settlement was only $27 \%$ reduced in TWS as a whole.

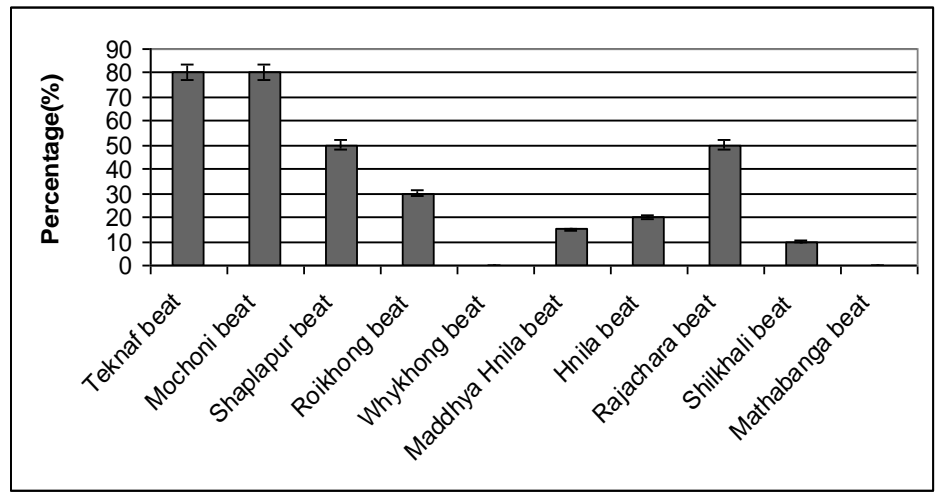

Fig. 4. Reduction of encroachment for crop field in TWS

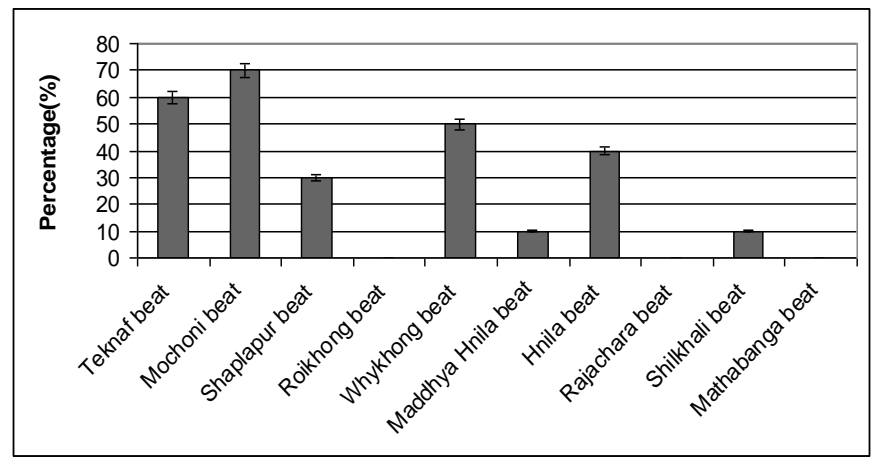

Fig. 5. Reduction of encroachment for settlement in TWS

Due to the high pressure of population people entered into the forest with organized group and gradually cleared the land to build houses and occupied the area. Political influence is one of the major challenges to reduce the encroachment for settlements at TWS.

Forest land encroachment, particularly near the flat and gently sloping boundaries around the game reserve (GR) of Teknaf, human settlements are increasing day by day. To execute this, the village elites are directly or indirectly associated with forest land grabbing. As per the official records of FD, 350.0 ha of forest land has been encroached in Whykhong (86.50 acres encroached by 258 persons), Shilkhali (500.0 ha encroached by 1100 persons) and Teknaf (200.0ha encroached by 848 persons).

\section{e. Livestock grazing}

Interestingly, this study found that only, on an average, $27 \%$ livestock's grazing was reduced in TWS (Figure $6)$. The highest reduction was at Mochoni (90\%) and lowest at Roikhong, and Maddya Hnila (10\%).

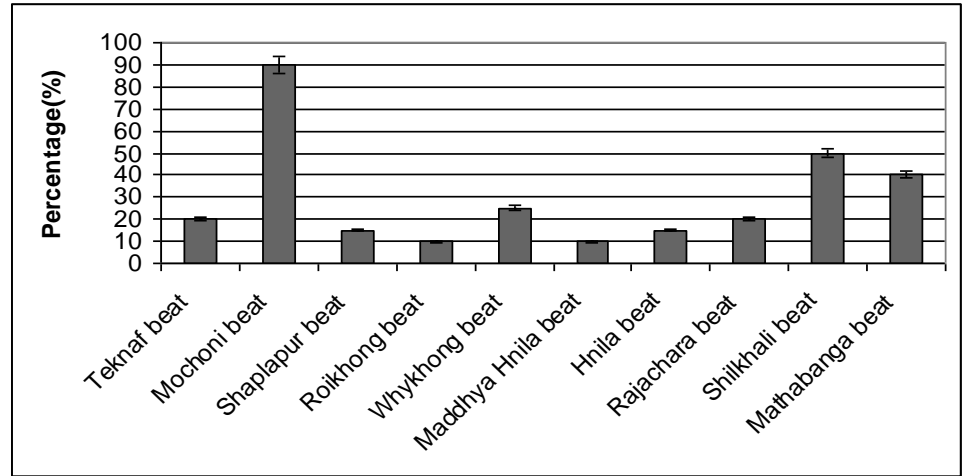

Fig. 6. Reduction of grazing of livestock in TWS 
Although it is one the severe threats for conservation of biodiversity of TWS, only at Mochoni beat was successful compared to others beat. Overall reduction of grazing of livestock at TWS was relatively low due to about $80 \%$ of the livestock in this area are fully dependent on young seedlings, herbs and grass which is grown in TWS. Forest Department in association with local NGOs are trying to improve this worsen situation at a satisfactory level.

\section{f. Hunting of wild animals}

The study also found that the highest reduction of hunting was at Teknaf $80 \%$ while lowest at Hnila $(66 \%)$ (Figure 7). Considering the all beats, on an average, the reduction of hunting in TWS was reduced. Although a few years ago, Elephant, Tiger, Deer, Wild Boar, Rabbit, Monkey, Jackle, Python, Various types of mammals were available at TWS, but now number of birds and wild animals has decreased dramatically and animals are hardly be seen. Local people used to access into the forest for hunting purpose. As a symbol of heroism, dignity, local people used to hunt wild Tiger, Deer, etc. Some smuggler hunt wild animal to collect their skin, bones, teeth, venom. Still people make traps with net to catch Deer and other animal. After visiting every beat of Teknaf, we found that this threat is still continued.

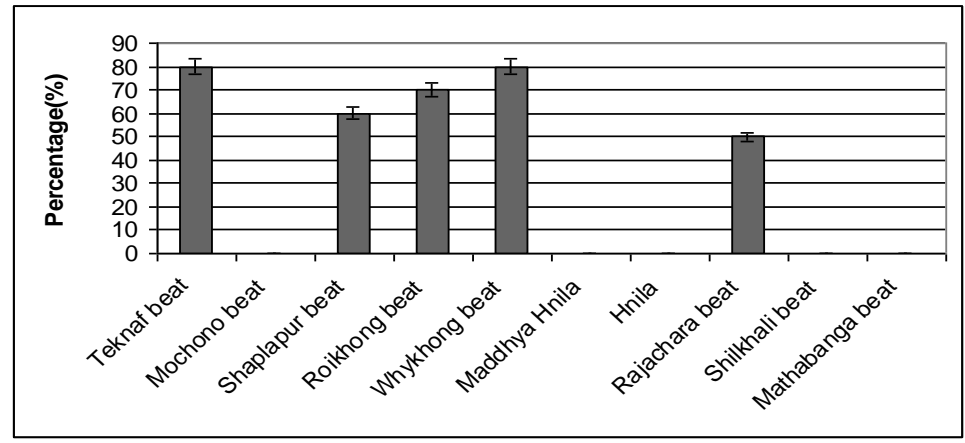

Fig. 7. Reduction of hunting in TWS.

\subsection{Threat Reduction Assessment (TRA) Index}

Highest TRA Index were found in Mathabhanga beat $(69.24 \%)$ where lowest were in Maddhya Hnila $(15.83 \%)$. On the other hand, TRA index was at Hnila,
Shaplapur and Shilkhali was 20.46, 26.98\% and, $27.46 \%$ respectively (Figure 8 ). Considering all the beats, the overall TRA index was $39.25 \%$ in TWS.

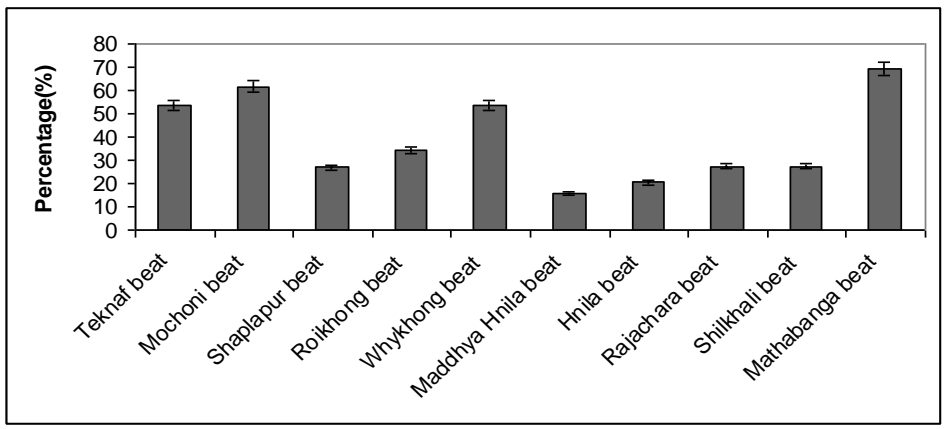

Fig. 8. Threat reductions in TWS

Although Forest Department (FD) of Bangladesh and Nishorgo have been working to reduce the threat at TWS for conserving its biodiversity, but still threats are so severe in in Maddhya, Hnila, Shaplapur, Shilkhali (Fig 7). We investigated that it is very difficult to eradicate all the threats on biodiversity in study area due to high density of population and poverty.

\section{Conclusion}

Teknaf Wildlife Sanctuary (TWS) is one of the PAs of Bangladesh which houses a very rich forest biodiversity. But, over the time, the natural resources of this sanctuary is depleting day by day. Government therefore needs to focus on co-management system.
Consequently, this study aims to listing the existing threats and assessment of threat reduction index at this sanctuary through key informants interview and FGDs. We found that six threats are the major reasons for depletion of natural resources at TWS. With the collaboration of Forest Department of Bangladesh and IPAC, USAID supported program, has been working to reduce these threats involving the local communities in the name of co-management of TWS. We found that, threat reduction index was about 39\%. Despite of active initiatives by the implemented co-management authorities, due to some local political leaders, social elites and natural resource dependent poor people around this sanctuary, the threat reduction rate was slow down. We sincerely believe that income generating activities (IGA) for the dependent 
communities, adequate funding for the threat reduction initiatives, arranging training for the local people about biodiversity conservation and commitment of local leaders, political leaders and elites people for the conservation of biodiversity of this area should be designed based on a threats analysis.

\section{References}

Arnold, J. E. M and Ruiz Pérez, M. 1999. The Role of Non-timber Forest Products in Conservation and Development. In: Wollenberg E. \& Ingles A. (eds.) Incomes from the Forests - methods for the development and conservation of forest products for local communities.

BFD, 2014. Protected areas in Bangladesh, available at:http://www.bforest.gov.bd/index.php/protect ed-areas

Brown, C. and Durst, P. B. 2003. State of forestry in Asia and the Pacific- 2003, Status, changes and trends. FAO-RAP, Bangkok, Thailand. 88 pp.

Center for environment and geographic information system, 2011. Dhaka ,Bangladesh

Clay, J. 1992. Why Rainforest Crunch? Cultural Survival Quaterly, 16(2): 31-37.

FAO. 2010. Global forest resources assessment, 2010 - Main report. FAO Forestry Paper 163. Rome, Italy.(Also available atwww.fao.org/forestry/fra /fra2010/en/).

GOB (Government of Bangladesh),1993. Forestry Master Plan: Participatory Forestry. Asian Development Bank (TA No. 1355-BAN) UNDP/FAO/BGD 88/025. Dhaka, Bangladesh.
Government of Bangladesh, 2009. Government of Bangladesh Gazette notification no. pabama/parisha4/nishorgo/105/sting/2006/398dt.23/11/2009.

Ministry of Environment and Forest, Government of Bangladesh, Dhaka.

Hirakuri, S. R. 2003. Can Law Save the Forests? Lessons from Finland and Brazil. CIFOR, Bogor, Indonesia. 120 pp.

IPAC, 2009. Teknaf Peninsula Community based ecotourism strategy, Co-management of protected areas of Bangladesh, pp 54.

Rahman, A. 2011.Integrated protected Area CoManagement in TWS.

Richard and Nicksalaski, (2001). A guide to threat reduction assessment for conservation. Biodiversity support programme ,Wasington DC.

Roy, M. K. 2004). Designing a Co-Management Model for Protected Areas in Bangladesh, Paper presented in seminar on Protected area management, University of Montana, USA.

Roy, M. K. 2005. Nishorgo Support Project: Designing a Co-management Model for the Protected Areas of Bangladesh. In: Nishorgo, Protected Area Management Program of Bangladesh. Dhaka, Bangladesh.1-5 pp.

Ruiz Pérez, M. (2005). Poverty Alleviation and Forest Conservation: The Role of Non-Timber Forest Products. In: Pfund, J.L. and Robinson, P. (eds). Non-Timber Forest Products betwwn poverty alleviation and market forces. InterCooperation, Switzerland. 8-13pp. 